\title{
Possible association of norepinephrine transporter -3081(A/T) polymorphism with methylphenidate response in attention deficit hyperactivity disorder
}

Boong-Nyun Kim, Jae-Won Kim*, Soon Beom Hong, Soo-Churl Cho, Min-Sup Shin, Hee-Jeong Yoo

\begin{abstract}
Background: Attention-deficit/hyperactivity disorder (ADHD) is a heritable disorder characterized by symptoms of inattention and/or hyperactivity/impulsivity. Methylphenidate (MPH) has been shown to block the norepinephrine transporter (NET), and genetic investigations have demonstrated that the norepinephrine transporter gene (SLC6A2) is associated with ADHD. The aims of this study were to examine the association of the SLC6A2 -3081(A/T) and G1287A polymorphisms with MPH response in ADHD.
\end{abstract}

Methods: This study enrolled 112 children and adolescents with ADHD. A response criterion was defined based on the Clinical Global Impression-Improvement (CGI-I) score, and the ADHD Rating Scale-IV (ARS) score was also assessed at baseline and 8 weeks after MPH treatment.

Results: We found that the subjects who had the $T$ allele as one of the alleles (A/T or T/T genotypes) at the -3081 (A/T) polymorphism showed a better response to MPH treatment than those with the A/A genotype as measured by the CGI-I. We also found a trend towards a difference in the change of the total ARS scores and hyperactivity/ impulsivity subscores between subjects with and without the $T$ allele. No significant association was found between the genotypes of the SLC6A2 G1287A polymorphism and response to ADHD treatment.

Conclusion: Our findings provide evidence for the involvement of the -3081(A/T) polymorphism of SLC6A2 in the modulation of the effectiveness of MPH treatment in ADHD.

\section{Background}

Attention-deficit/hyperactivity disorder (ADHD) is a heritable neurodevelopmental disorder affecting about 3-7\% of children with its symptoms of inattention and/ or hyperactivity/impulsivity [1]. Methylphenidate (MPH) has been reported to reduce ADHD symptoms in approximately $70 \%$ of children with ADHD [2,3], and has been used for the treatment of the disorder for more than 60 years [4]. It has been well recognized that the mode of action of MPH in ADHD treatment is in its blockade of not only the dopamine transporter (DAT) [5] but also the norepinephrine transporter (NET) [6]. One recent study examined if $\mathrm{MPH}$

\footnotetext{
* Correspondence: adore412@paran.com

Division of Child and Adolescent Psychiatry, Department of Psychiatry, Seoul National University College of Medicine, Seoul, Republic of Korea
}

potentially blocked the human and mouse NET, and indeed reported the sensitivity of the NET to MPH as being similar to that of the DAT [7]. Andrews and Lavin [8] demonstrated that the MPH-induced increase in cortical cell excitability is mediated by activation of alpha-2-adrenergic receptors, and they suggested the possibility of the therapeutic actions of stimulants being associated with preferential activation of noradrenergic and/or dopaminergic neurotransmission within the prefrontal cortex.

In the prefrontal cortex, where DAT density is low and NET density is higher, it is unlikely that blockade of the DAT is a significant contributor to elevated DA levels in this region. It has been postulated that DA is transported by the NET in the prefrontal cortex, since DA has a higher affinity for the NET as compared with 
its affinity for the DAT [9]. DAT-selective (MPH), DAT/ NET-selective (amphetamine), or NET-selective (atomoxetine) ADHD medications have one pharmacological effect in common, which is to elevate extracellular levels of DA and NE in the prefrontal cortex [10].

The norepinephrine transporter gene (SLC6A2), located on chromosome 16q12.2, is composed of 14 exons spanning $48 \mathrm{~kb}$, predicting a protein of 617 amino acids. It has been suggested as one of the candidate genes associated with ADHD [11]. Recently, Kim et al. [12] demonstrated a -3081 A to T single nucleotide polymorphism (rs28386840) in the promoter region of the SLC6A2 and its association with ADHD. This study also identified the $-3081(\mathrm{~A} / \mathrm{T})$ polymorphism as a functional polymorphism that decreases promoter function. According to a study by Yang et al. [13], the G1287A polymorphism (rs5569), at exon 9 of the SLC6A2, was identified to be associated with MPH response during the treatment of ADHD. Our previous study [14] provided evidence for the possible involvement of the SLC6A2 -3081(A/T) polymorphism in the expression of ADHD symptoms, such as increased variability in response time performance. However, in our study, the family-based and case-control association analyses of the $-3081(\mathrm{~A} / \mathrm{T})$ and G1287A polymorphisms of the SLC6A2 found no significant association of these two polymorphisms with ADHD. Recently, the finding of no significant effect for SLC6A2 G1287A SNP was reproduced by McGough et al. [15].

Pharmacogenetic studies aim to identify genetic variations associated with drug treatment response or adverse effects secondary to medication $[16,17]$. There is growing interest in the pharmacogenetics of ADHD and, until recently, most of the investigations had focused on the potential susceptibility genes for ADHD, mainly the genes associated with the dopaminergic systems [18]. Neurobiological and pharmacological evidence points to dysregulation of the central noradrenergic systems as the underlying pathophysiology of ADHD [19]. The presumed mechanism of action of atomoxetine, which has shown clinical efficacy in treating ADHD patients, involves the selective norepinephrine reuptake inhibitor functions [20]. More precisely, atomoxetine is known to be more specific of the NET than the DAT, which stresses the rationale for the importance of further gene studies targeting the NET. This evidence supports the importance for a comprehensive assessment of the SLC6A2 in ADHD. In addition, the SLC6A2 is therefore also a likely candidate to assess genetic contributions to variability in ADHD treatment response. To our knowledge, most of the pharmacogenetic studies of SLC6A2 in ADHD have been conducted on Western populations $[11,13,21]$, and there have been no studies on the association between the SLC6A2 -3081(A/T) polymorphism and the response to MPH treatment. The aims of this study were to examine the association of the SLC6A2 -3081(A/T) and G1287A polymorphisms with $\mathrm{MPH}$ response in children and adolescents with ADHD.

\section{Methods}

\section{Subjects and clinical assessments}

The participants of the present study were recruited from the Department of Child and Adolescent Psychiatry at Seoul National University Hospital in Korea. The diagnostic procedures in our unit have been described elsewhere [14]. In brief, ADHD was diagnosed based on the DSM-IV criteria using the Kiddie-Schedule for Affective Disorders and Schizophrenia-Present and Lifetime Version (K-SADS-PL) [22,23]. Subjects with (1) a history of, or a current neurological disease, including convulsive disorder, or (2) any evidence of a comorbid psychiatric condition, such as Tourette's disorder, mental retardation, pervasive developmental disorder, bipolar disorder, psychosis, language difficulties or learning disabilities, were excluded. Of the DSM-IV subtypes of ADHD, the combined subtype was the most common in our subjects (61.6\%), followed by the inattentive (25.9\%) and hyperactive-impulsive (5.4\%) subtypes. With regard to comorbidity, oppositional defiant disorder (13.4\%) was the most common, followed by anxiety disorder $(10.7 \%)$ and enuresis (4.5\%). For clinical evaluation of ADHD subjects, the ADHD Rating Scale-IV (ARS) [24,25] and Clinical Global Impression (CGI) [26] were administered. The ARS scores were checked by parents, and CGI scores were checked by psychiatrists.

The study was approved by the institutional review board (IRB) for human subjects at the Seoul National University Hospital. Parents provided written informed consent, and the children or adolescents provided verbal assent regarding participation in this study.

\section{MPH administration and treatment response}

All of the ADHD subjects were administered MPH for a total of 8 weeks. We adjusted the MPH doses at the 2nd and the 4th week. The dosages were increased until doses were reached that were sufficient to achieve therapeutic effect, on the basis of the parents' reports of symptom improvement and side effects, and then these doses were maintained for the remaining of 8 weeks. Following Cheon et al. [27,28], clinical assessments were performed by psychiatrists at baseline prior to medication and after 8 weeks of MPH treatment in order to assess the improvement of ADHD symptoms. A "good" response was defined a priori as a CGI-I score of 1 or 2 points after MPH treatment, whereas a "poor" response was defined as a CGI-I score in the range of 3-7 points; the dichotomous response criterion was our primary outcome measurement $[28,29]$. We established strong 
inter-rater reliability before the start of medication $($ kappa $=0.89)$. Psychiatrists were blind to patients' genotypes.

\section{Genotyping}

Genomic DNA was extracted from whole blood lymphocytes using a G-DEX TM II Genomic DNA Extraction Kit (Intron, Korea). The detection of a single nucleotide polymorphism was based upon analysis of primer extension products generated from previously amplified genomic DNA, using a chip-based matrixassisted laser desorption/ionization time-of-flight (MALDI-TOF) mass spectrometry platform (Sequenom, California, USA). The SLC6A2 polymorphisms were genotyped as previously described $[12,13]$, with slight modifications. In brief, oligonucleotide primers [5'-ACG TTG GAT GAG ACC CTA ATT CCT GCA CCC, and 5'-ACG TTG GAT GTT CAG GAC CTG GAA GTC ATC for the G1287A polymorphism; 5'-ACG TTG GAT GGT TTT CTT GCC CCT CAA GTG, and 5'-ACG TTG GAT GAG GGA AGG AAA CCA GGA GAA for the $-3081(\mathrm{~A} / \mathrm{T})$ polymorphism] were used to generate polymerase chain reaction (PCR) products. The PCR was performed in a volume of $5 \mu$ l containing $1 \times$ PCR buffer (TAKARA, Japan), $2.5 \mathrm{mM} \mathrm{MgCl} 2,0.2 \mathrm{mM}$ of each dNTP, 0.1 U HotStar Taq Polymerase (Qiagen, Germany), $8 \mathrm{pM}$ of each primer, and $4.0 \mathrm{ng}$ of genomic DNA. The reaction consisted of denaturation at $95^{\circ} \mathrm{C}$ for $15 \mathrm{~min}$, followed by 45 cycles at $95^{\circ} \mathrm{C}$ for $20 \mathrm{sec}, 56^{\circ}$ $\mathrm{C}$ for $30 \mathrm{sec}$, and $72^{\circ} \mathrm{C}$ for $1 \mathrm{~min}$, with a final extension at $72^{\circ} \mathrm{C}$ for $3 \mathrm{~min}$. Following the PCR, unincorporated dNTP was removed by the addition of $0.3 \mathrm{U}$ of shrimp alkaline phosphatase and incubation for $20 \mathrm{~min}$ at $37^{\circ} \mathrm{C}$, followed by $5 \mathrm{~min}$ at $85^{\circ} \mathrm{C}$ for enzyme inactivation. The total volume of each reaction was $9 \mu$, including hME enzyme (Thermo Sequenase, GE Healthcare, UK), ACT termination mix, and $5 \mathrm{uM}$ of extension primer. The primer extension protocol was started at $94^{\circ} \mathrm{C}$ for $2 \mathrm{~min}$, followed by 55 cycles at $94^{\circ} \mathrm{C}$ for $5 \mathrm{sec}, 52^{\circ} \mathrm{C}$ for $5 \mathrm{sec}$, and $72^{\circ} \mathrm{C}$ for $5 \mathrm{sec}$. After desalting of the reaction products with SpectroCLEAN (Sequenom), samples were analyzed in the fully automated mode with the MALDITOF MassARRAY system (Bruker-Sequenom, California, USA). We used blank and negative control for each genotyping plate. For quality control of genotyping data, duplicate testing of $10 \%$ ( 11 samples) of randomly selected samples was performed in a blind manner. No discrepancies were found.

\section{Statistical analysis}

Allele frequencies were estimated by counting, and the Hardy-Weinberg equilibrium was calculated based on these allele frequencies, using the goodness-of-fit $\chi^{2}$ test. The estimation of allele frequencies and the test for the
Hardy-Weinberg equilibrium were conducted for the genotypes of all subjects.

Group differences in the clinical variables involving continuous data were computed using an independent two sample t-test or one-way analysis of variance (ANOVA). Between-group comparisons involving categorical data were assessed using the $\chi^{2}$ test or Fisher's exact test. We used the ANOVA and t-test to assess correlation between the genotype of SLC6A2 and the change in the ARS scores in ADHD subjects after MPH treatment. Predictors of MPH response were tested using univariate analysis of variance with general linear model procedure: the dependent variable was the CGI-I score, and the fixed factors were gene, final MPH dose, and gene $\times$ dose interaction. Effect size estimates for MPH response were based on Cohen $f^{2}$. The significance level was set at $\mathrm{p}=0.05 / 2$ (SNPs) ${ }^{*} 2$ (outcome measures $)=0.01$. Power analysis was performed using G*Power 3 (Heinrich-Heine-University, Dusseldorf, Germany).

\section{Results}

\section{Demographic and clinical characteristics}

One hundred and twelve ADHD subjects (mean age = $9.1 \pm 2.1$ years) were enrolled, consisting of 92 boys $(82.1 \%)$ and 20 girls (17.9\%) (Table 1). The average total IQ of the ADHD subjects was $107.4 \pm 13.7$. The average score of overall ADHD symptoms according to the ARS, as measured by the parents of the ADHD subjects, was $26.9 \pm 10.3$. No baseline differences were found between the responders and non-responders in their demographic and clinical characteristics, including the ARS scores at study entry.

\section{Genetic polymorphisms of SLC6A2}

Among the 112 ADHD subjects, the genotype frequencies (A/A homozygous, A/T heterozygous, and $\mathrm{T} / \mathrm{T}$ homozygous) of the SLC6A2 -3081(A/T) polymorphism were $25.9 \%, 53.6 \%$, and $20.5 \%$, respectively (Table 2 ). The genotype frequencies (G/G homozygous, G/A heterozygous, and A/A homozygous) of the SLC6A2 G1287A polymorphism were $51.8 \%, 37.5 \%$, and $10.7 \%$, respectively. Genotype and allele frequencies observed in this study were comparable with previously reported values from the South Korean population [14]. The distribution of the genotypes for the SLC6A2 -3081(A/T) polymorphism and SLC6A2 G1287A polymorphism were in agreement with the expected values of the Hardy-Weinberg equilibrium ( $p>0.05)$.

Association between the genotypes of SLC6A2 and MPH response according to the CGI-I assessed by the clinician There was a trend for association between the genotypes of the SLC6A2 $-3081(\mathrm{~A} / \mathrm{T})$ polymorphism and 
Table 1 Demographic and clinical characteristics of subjects with ADHD

\begin{tabular}{|c|c|c|c|c|}
\hline & $\begin{array}{c}\text { ADHD } \\
(n=112)\end{array}$ & $\begin{array}{c}\text { Responders } \\
(\mathrm{n}=62)\end{array}$ & $\begin{array}{c}\text { Non-responders } \\
(\mathrm{n}=50)\end{array}$ & p-value \\
\hline Age in yr, mean (SD) & $9.1(2.1)$ & $9.1(2.0)$ & $9.0(2.2)$ & 0.79 \\
\hline $\operatorname{Sex}(M / F)$ & $92 / 20$ & $54 / 8$ & $38 / 12$ & 0.13 \\
\hline $\mathrm{IQ}$, mean $(\mathrm{SD})$ & $107.4(13.7)$ & $107.8(13.2)$ & $106.9(14.4)$ & 0.73 \\
\hline ADHD subtypes & & & & 0.30 \\
\hline Combined & $61.6 \%$ & $58.1 \%$ & $66.0 \%$ & \\
\hline Inattentive & $25.9 \%$ & $25.8 \%$ & $26.0 \%$ & \\
\hline Hyperactive-impulsive & $5.4 \%$ & $4.8 \%$ & $6.0 \%$ & \\
\hline NOS & $7.1 \%$ & $11.3 \%$ & $2.0 \%$ & \\
\hline \multicolumn{5}{|l|}{ Comorbidity } \\
\hline Oppositional defiant disorder & $13.4 \%$ & $8.0 \%$ & $20.0 \%$ & 0.07 \\
\hline Anxiety disorder & $10.7 \%$ & $9.7 \%$ & $12.0 \%$ & 0.69 \\
\hline Enuresis & $4.5 \%$ & $6.5 \%$ & $2.0 \%$ & 0.26 \\
\hline \multicolumn{5}{|l|}{ ARS baseline scores, mean (SD) } \\
\hline Total & $26.9(10.3)$ & $25.9(11.1)$ & $28.3(8.8)$ & 0.23 \\
\hline Inattentive & $15.1(5.8)$ & $14.2(5.9)$ & $16.3(5.6)$ & 0.07 \\
\hline Hyperactivity/impulsivity & $11.8(6.0)$ & $11.6(6.3)$ & $12.0(5.7)$ & 0.75 \\
\hline \multicolumn{5}{|l|}{ Dosage of MPH (mg/day), mean (SD) } \\
\hline Baseline dose & $19.9(8.3)$ & $18.6(6.2)$ & $21.5(10.1)$ & 0.08 \\
\hline Final 2 weeks dose & $29.2(11.6)$ & $28.2(10.9)$ & $30.4(12.4)$ & 0.32 \\
\hline
\end{tabular}

ADHD, Attention-Deficit/Hyperactivity Disorder; NOS, Not Otherwise Specified; ARS, ADHD Rating Scale; MPH, Methylphenidate

response to ADHD treatment. Of the subjects who had the $\mathrm{T}$ allele as one of the alleles ( $\mathrm{A} / \mathrm{T}$ or $\mathrm{T} / \mathrm{T}$ genotypes) at the $-3081(\mathrm{~A} / \mathrm{T})$ polymorphism, $61.4 \%$ (51 of 83 ) showed a good response (CGI-I $=1$ or 2 ) to MPH treatment. However, only $37.9 \%$ (11 of 29 ) of the subjects with the A/A genotype showed a good response to MPH treatment (Pearson $\left.\chi^{2}(1)=4.81, \mathrm{p}=0.03\right)$ (Table $2)$. The power to detect differences at the 0.01 level of significance with our sample size of 112 was 0.35 . No significant association was found between the genotypes of the SLC6A2 G1287A polymorphism and response to ADHD treatment.

We found no significant gene effect $\left(F_{2,80}=0.49\right.$, $\left.\mathrm{p}=0.61, f^{2}=0.01\right)$ or gene $\times$ dose interaction $\left(F_{13,80}=\right.$ $\left.1.19, \mathrm{p}=0.30, f^{2}=0.19\right)$ for the SLC6A2 $-3081(\mathrm{~A} / \mathrm{T})$ polymorphism on MPH response.

Table 2 Association between SLC6A2 genotypes and response to MPH treatment according to the CGI-I

\begin{tabular}{|c|c|c|c|c|c|}
\hline & \multirow[b]{2}{*}{ SLC6A2 genotype } & \multicolumn{2}{|c|}{$\begin{array}{c}\text { Response to MPH by CGI-I } \\
\mathrm{N} \text { (\% within SLC6A2 genotype) }\end{array}$} & \multirow[b]{2}{*}{$\begin{array}{c}\text { Total } \\
\text { (\% within total number) }\end{array}$} & \multirow[b]{2}{*}{$p$-value } \\
\hline & & $\begin{array}{c}\text { Poor } \\
\text { (CGI-I: } 3-7)\end{array}$ & $\begin{array}{c}\text { Good } \\
\text { (CGI-I: } 1 \text { or } 2)\end{array}$ & & \\
\hline \multirow[t]{6}{*}{-3081(A/T) polymorphism } & $\mathrm{A} / \mathrm{A}$ & $18(62.1 \%)$ & $11(37.9 \%)$ & $29(25.9 \%)$ & 0.08 \\
\hline & $\mathrm{A} / \mathrm{T}$ & $24(40.0 \%)$ & $36(60.0 \%)$ & $60(53.6 \%)$ & \\
\hline & $\mathrm{T} / \mathrm{T}$ & $8(34.8 \%)$ & $15(65.2 \%)$ & $23(20.5 \%)$ & \\
\hline & $\mathrm{A} / \mathrm{A}$ & $18(62.1 \%)$ & $11(37.9 \%)$ & $29(25.9 \%)$ & 0.03 \\
\hline & $\mathrm{A} / \mathrm{T}+\mathrm{T} / \mathrm{T}$ & $32(38.6 \%)$ & $51(61.4 \%)$ & $83(74.1 \%)$ & \\
\hline & Total & $50(44.6 \%)$ & $62(55.4 \%)$ & 112 & \\
\hline \multirow[t]{6}{*}{ G1287A polymorphism } & $\mathrm{G} / \mathrm{G}$ & $22(37.9 \%)$ & $36(62.1 \%)$ & $58(51.8 \%)$ & 0.12 \\
\hline & $\mathrm{G} / \mathrm{A}$ & $24(57.9 \%)$ & $18(42.9 \%)$ & $42(37.5 \%)$ & \\
\hline & $\mathrm{A} / \mathrm{A}$ & $4(33.3 \%)$ & $8(66.7 \%)$ & $12(10.7 \%)$ & \\
\hline & $\mathrm{G} / \mathrm{G}$ & $22(37.9 \%)$ & $36(62.1 \%)$ & $58(51.8 \%)$ & 0.14 \\
\hline & $\mathrm{G} / \mathrm{A}+\mathrm{A} / \mathrm{A}$ & $28(51.9 \%)$ & $26(48.1 \%)$ & $54(48.2 \%)$ & \\
\hline & Total & $50(44.6 \%)$ & $62(55.4 \%)$ & 112 & \\
\hline
\end{tabular}


Association between the genotypes of the $-3081(\mathrm{~A} / \mathrm{T})$ polymorphism and MPH response according to the ARS as assessed by the parents

There were no significant differences in the demographic and clinical characteristics, except the profile of comorbid enuresis, between the ADHD subjects with the $(\mathrm{A} / \mathrm{T}+\mathrm{T} / \mathrm{T})$ genotypes and those with the $\mathrm{A} / \mathrm{A}$ genotype of the $-3081(\mathrm{~A} / \mathrm{T})$ polymorphism (Table 3$)$.

When we compared the changes in ARS scores after $\mathrm{MPH}$ treatment as the secondary outcome measurement, according to the genotypes of the $-3081(\mathrm{~A} / \mathrm{T})$ polymorphism, we found a trend towards a difference in the change of the total ARS scores $[\mathrm{t}(1)=1.92$, $\mathrm{p}=0.06]$ and hyperactivity/impulsivity subscores $[\mathrm{t}(1)=1.73, \mathrm{p}=0.09]$ between subjects with and without the $\mathrm{T}$ allele (Table 4 ).

\section{Discussion}

In this study, we identified a trend for association between the $-3081(\mathrm{~A} / \mathrm{T})$ polymorphism of $S L C 6 A 2$ and response to $\mathrm{MPH}$ treatment in Korean children and adolescents with ADHD. Those ADHD subjects who had the $\mathrm{T}$ allele as one of the alleles $(\mathrm{A} / \mathrm{T}$ or $\mathrm{T} / \mathrm{T}$ genotypes) at the $-3081(\mathrm{~A} / \mathrm{T})$ polymorphism showed a better response to $\mathrm{MPH}$ treatment than those with the A/A genotype, although this relative difference does not provide definite conclusion on whether the presence of the
Table 4 Comparison reductions in ARS scores after MPH treatment in ADHD subjects according to genotypes of the $-3081(A / T)$ polymorphism

\begin{tabular}{lcccccc}
\hline Genotype & \multicolumn{6}{c}{ Changes in ARS scores } \\
\cline { 2 - 7 } & IA & p-value & Hy/Imp & p-value & Total & p-value \\
\hline A/A & $5.4(4.3)$ & 0.54 & $4.6(4.1)$ & 0.12 & $8.4(7.6)$ & 0.10 \\
$\mathrm{~A} / \mathrm{T}$ & $6.2(4.9)$ & & $6.3(4.5)$ & & $12.1(8.8)$ & \\
$\mathrm{T} / \mathrm{T}$ & $7.2(6.6)$ & & $7.8(7.2)$ & & $14.7(12.6)$ & \\
$\mathrm{A} / \mathrm{A}$ & $5.4(4.3)$ & 0.38 & $4.6(4.1)$ & 0.09 & $8.4(7.6)$ & 0.06 \\
$\mathrm{~A} / \mathrm{T}+\mathrm{T} / \mathrm{T}$ & $6.5(5.4)$ & & $6.7(5.4)$ & & $12.8(10.0)$ & \\
\hline
\end{tabular}

ARS, ADHD Rating Scale; IA, inattentive subscale; Hy/Imp, hyperactivity/ impulsivity subscale

All values are mean $( \pm$ S.D.)

$\mathrm{T}$ allele is association with a better response or the absence of the $\mathrm{T}$ allele is associated with a poorer response, given that even the ADHD patients with the $\mathrm{T}$ allele showed only a $61.4 \%$ response rate to MPH. In addition, the ADHD subjects with the $\mathrm{T}$ allele showed a tendency for more symptom reduction after treatment with MPH than those without the T allele. However, no significant association was found between response to $\mathrm{MPH}$ and the SLC6A2 G1287A polymorphism. In a previous study [13], those ADHD subjects who were homozygous for the A allele (A/A genotype) at the G1287A polymorphism showed less symptom reduction in the hyperactive-impulsive subscores of the ARS after

Table 3 Demographic and clinical characteristics of ADHD subjects according to genotypes of the $-3081(A / T)$ polymorphism

\begin{tabular}{|c|c|c|c|}
\hline & $\begin{array}{l}\text { ADHD subjects with } \\
\text { A/A genotype }\end{array}$ & $\begin{array}{c}\text { ADHD subjects with } A / T \\
+T / T \text { genotypes }\end{array}$ & p-value \\
\hline Age in yr, mean (SD) & $9.0(2.4)$ & $9.1(2.0)$ & 0.81 \\
\hline $\operatorname{Sex}(M / F)$ & $22 / 7$ & $70 / 13$ & 0.31 \\
\hline $\mathrm{IQ}$, mean $(\mathrm{SD})$ & $107.2(13.3)$ & $107.5(14.0)$ & 0.92 \\
\hline ADHD subtypes & & & 0.35 \\
\hline Combined & $58.6 \%$ & $62.7 \%$ & \\
\hline Inattentive & $34.5 \%$ & $22.9 \%$ & \\
\hline Hyperactive-impulsive & $0.0 \%$ & $7.2 \%$ & \\
\hline NOS & $6.9 \%$ & $7.2 \%$ & \\
\hline \multicolumn{4}{|l|}{ Comorbidity } \\
\hline Oppositional defiant disorder & $6.9 \%$ & $15.7 \%$ & 0.19 \\
\hline Anxiety disorder & $3.4 \%$ & $13.3 \%$ & 0.13 \\
\hline Enuresis & $13.8 \%$ & $1.2 \%$ & 0.02 \\
\hline \multicolumn{4}{|l|}{ ARS baseline scores, mean (SD) } \\
\hline Total & $23.9(11.4)$ & $27.9(9.7)$ & 0.08 \\
\hline Inattentive & $13.6(6.3)$ & $15.6(5.6)$ & 0.12 \\
\hline Hyperactivity/impulsivity & $10.3(6.9)$ & $12.3(5.7)$ & 0.14 \\
\hline \multicolumn{4}{|l|}{ Dosage of MPH (mg/day), mean (SD) } \\
\hline Baseline dose & $19.7(9.3)$ & $20.0(8.0)$ & 0.88 \\
\hline Final 2 weeks dose & $27.9(11.1)$ & $29.7(11.8)$ & 0.48 \\
\hline CGIII score, mean (SD) & $2.8(0.9)$ & $2.4(0.8)$ & 0.04 \\
\hline
\end{tabular}

ADHD, Attention-Deficit/Hyperactivity Disorder; NOS, Not Otherwise Specified; ARS, ADHD Rating Scale; MPH, Methylphenidate 
treatment with $\mathrm{MPH}$ than those with the other genotypes (G/G or G/A genotypes). The sample size of their study ( 35 boys and 10 girls) was smaller than that of our study (92 boys and 10 girls). The divergent results between the two studies might reflect methodological issues, such as sample sizes, ethnic differences, inclusion and exclusion criteria, or instruments to assess drug treatment response.

It is important to understand the potential functional significance of the SLC6A2 -3081(A/T) polymorphism. Kim et al. [12] reported that the $-3081(\mathrm{~T})$ allele significantly decreases promoter function compared with the -3081(A) allele, which was assessed using synthesized promoter-reporter constructs. The authors also demonstrated that Slug and Scratch, neural-expressed transcriptional repressors, decrease the promoter activity only when it contains the -3081(T) allele. In their study, the frequency of the $-3081(\mathrm{~T})$ allele was significantly higher in the ADHD probands than in the controls, and the $A / T$ and $T / T$ genotypes were overrepresented in the ADHD subjects. However, studies of the association between SLC6A2 -3081(A/T) polymorphism and ADHD have yielded mixed results, with several studies finding some evidence for association [12,27], and our previous paper providing no evidence for association [14]. Recently, Jung et al. [30] reproduced in a Korean population that the frequency of the $-3081(\mathrm{~T})$ allele was significantly higher in ADHD subjects than in controls. Our current data that the ARS total score at baseline showed a higher trend $(\mathrm{p}=0.08)$ in those with at least one -3081(T) allele might slightly support the previous findings from the Korean population. Downregulated promoter function of $S L C 6 A 2$ and consequent decrease in transcriptional activity, as reported by Kim et al. [12], may result in low levels of NET. Our results, which suggest a good response to MPH in ADHD is associated with the presence of the $-3081(\mathrm{~T})$ allele of $S L C 6 A 2$, may be explained by reduced levels of NET within the brain. On the other hand, it is possible that subjects with the $-3081(\mathrm{~T})$ allele have their ADHD in tighter relation with the action of NET, and therefore pharmacologically blocking this transporter is associated with relatively better treatment response. Thus, investigating response to treatment and its mechanism of action in terms of molecular and genetic findings might help us to identify more homogeneous subgroups of ADHD [31]. Further studies using imaging genetic approaches based on single photon emission computerized tomography (SPECT) or positron emission tomography (PET) will be required to investigate NE gene effects on regional cerebral perfusion or metabolism in ADHD and to evaluate the association of SLC6A2 genetic variation with levels of $\mathrm{NE}$ activity in the brain.
The search for candidate genes associated with ADHD has been largely driven by the understanding that medications for this disorder have drug targets in the catecholamine neurotransmitter systems [32]. Although knowledge about the presumed mechanisms of action of ADHD medication, including MPH, initially informed the research into genetic polymorphisms associated with the disorder, these same polymorphisms have been and continue to be logical candidates to predict medication outcome, in terms of symptom response and side effect profiles [33]. Recent studies suggest that candidate genes involved in catecholamine pathways influence individual responses to ADHD treatments. However, as mentioned above, the majority of pharmacogenetic studies of ADHD investigating response or tolerability to medication have focused mainly on dopaminergic genes [11]. Polymorphisms in noradrenergic genes, such as alpha-2A-adrenergic receptor gene $(A D R A 2 A)$ or $S L C 6 A 2$, may have a specific effect as proposed on MPH response [13,21,34]. Mick et al. [21] have conducted a genome-wide association study (GWAS) on a sample of 187 ADHD children and found that 2 SNPs that tag NET gene (SLC6A2) were suggestively association with MPH response. On the other hand, in a study conducted by Kooij et al. [35], the polymorphisms in the SLC6A2 were not associated with MPH response. Here, of note is that the study by Ramoz et al. [11] has demonstrated that the SLC6A2 predicted response to another pharmacological agent for ADHD: atomoxetine. In these contexts, our findings demonstrate that the -3081(A/T) polymorphism of SLC6A2 might modulate the effectiveness of MPH treatment on ADHD. To date, this study is the first to examine the association of the SLC6A2 -3081(A/T) polymorphism with MPH response in ADHD. The result of Ramoz et al. [11] and ours combined further suggest that the SLC6A2 -3081(A/T) polymorphism constitute a common pathway for the treatment effects of both MPH and atomoxetine.

Several limitations to this study should be noted. First, this was a naturalistic study, and we did not have a placebo arm in this trial. It is likely that a placebo response in our study group would have decreased the statistical power by reducing the measurement precision of $\mathrm{MPH}$ response. However, naturalistic study designs may be valuable to better appreciate the role of genetic factors in routine clinical practice beyond the realm of controlled clinical trials. Second, our study population included all of the subtypes of ADHD, which might have contributed to clinical heterogeneity; the subtypes may have acted as potential confounders of the investigated association. Third, MPH was administered with no control of adherence by investigators. Fourth, we did not control for the two types of MPH products: immediate-release (IR) 
$\mathrm{MPH}$ and sustained-release (SR) MPH. However, we did not find a significant difference in clinical improvement between the ADHD subjects treated with IR MPH and those treated with SR MPH (data not shown, but available upon request). Lastly, but perhaps most importantly, two titration visits in our study design were probably insufficient, which may have resulted in lower mean daily doses at endpoint, and it might explain the low response rate observed in our results compared to the reported average response rate of approximately $75 \%$ in controlled outpatient stimulant trials [36].

\section{Conclusion}

In conclusion, our data suggest that the $-3081(\mathrm{~A} / \mathrm{T})$ polymorphism of SLC6A2 might be involved in the modulation of the effectiveness of MPH treatment in ADHD. Further pharmacogenetic investigations should expand the focus to include other functional polymorphisms of the $S L C 6 A 2$, given the increased use of noradrenergic drugs in the treatment of ADHD symptoms [37], in order to better understand the role of genetic variation in a good $v s$. poor response to drug treatment for ADHD.

\section{Acknowledgements}

This study is supported in part by the Seoul National University Hospital Research Fund (Grant No. 09-2008-001-0) and in part by the Korea Research Foundation Grant funded by the Korean Government (MOEHRD, Basic Research Promotion Fund) (KRF-2006-003- E00192).

\section{Authors' contributions}

BNK, JWK, SCC and HJY designed the study and participated in data collection. BNK, JWK and SBH analyzed the data, interpreted the results, and drafted the manuscript. SCC and MSS supervised the study. All authors read and approved the final manuscript.

\section{Competing interests}

The authors declare that they have no competing interests.

Received: 24 June 2010 Accepted: 7 October 2010

Published: 7 October 2010

\section{References}

1. American Psychiatric Association: Diagnostic and Statistical Manual of Mental Disorders Washington, DC: American Psychiatric Association, Fourth 1994.

2. Greenhill LL, Pliszka S, Dulcan MK, Bernet W, Arnold V, Beitchman J, et al: American Academy of Child and Adolescent Psychiatry. Practice parameter for the use of stimulant medications in the treatment of children, adolescents, and adults. J Am Acad Child Adolesc Psychiatry 2002, 41:S26-S49.

3. Wilens TE: Effects of methylphenidate on the catecholaminergic system in attention-deficit/hyperactivity disorder. J Clin Psychopharmacol 2008, 8: S46-S53.

4. Swanson JM, Sergeant JA, Taylor E, Sonuga-Barke EJ, Jensen PS, Cantwell DP: Attention-deficit hyperactivity disorder and hyperkinetic disorder. Lancet 1998, 351:429-433.

5. Spencer T, Biederman J, Wilens T, Harding M, O'Donnell D, Griffin S: Pharmacotherapy of attention-deficit hyperactivity disorder across the life cycle. J Am Acad Child Adolesc Psychiatry 1996, 35:409-432.

6. Solanto MV: Neuropsychopharmacological mechanisms of stimulant drug action in attention-deficit hyperactivity disorder: a review and integration. Behav Brain Res 1998, 94:127-152.
7. Han DD, Gu HH: Comparison of the monoamine transporters from human and mouse in their sensitivities to psychostimulant drugs. BMC Pharmacol 2006, 6:6.

8. Andrews GD, Lavin A: Methylphenidate increases cortical excitability via activation of alpha-2 noradrenergic receptors. Neuropsychopharmacology 2006, 31:594-601.

9. Madras BK, Miller GM, Fischman AJ: The dopamine transporter and attention-deficit/hyperactivity disorder. Biol Psychiatry 2005, 57:1397-1409.

10. Wilens TE: Drug therapy for adults with attention-deficit hyperactivity disorder. Drugs 2003, 63:2395-2411.

11. Ramoz N, Boni C, Downing AM, Close SL, Peters SL, Prokop AM, et al: A haplotype of the norepinephrine transporter (Net) gene Slc6a2 is associated with clinical response to atomoxetine in attention-deficit hyperactivity disorder (ADHD). Neuropsychopharmacology 2009, 34:2135-2142.

12. Kim CH, Hahn MK, Joung $Y$, Anderson SL, Steele AH, Mazei-Robinson MS, et al: A polymorphism in the norepinephrine transporter gene alters promoter activity and is associated with attention-deficit hyperactivity disorder. Proc Natl Acad Sci USA 2006, 103:19164-19169.

13. Yang L, Wang YF, Li J, Faraone SV: Association of norepinephrine transporter gene with methylphenidate response. J Am Acad Child Adolesc Psychiatry 2004, 43:1154-1158.

14. Cho SC, Kim JW, Kim BN, Hwang JW, Park M, Kim SA, et al: No evidence of an association between norepinephrine transporter gene polymorphisms and attention deficit hyperactivity disorder: a familybased and case-control association study in a Korean sample. Neuropsychobiology 2008, 57:131-138.

15. McGough JJ, McCracken JT, Loo SK, Manganiello M, Leung MC, Tietjens JR, et al: A Candidate Gene Analysis of Methylphenidate Response in Attention-Deficit/Hyperactivity Disorder. J Am Acad Child Adolesc Psychiatry 2009.

16. McGough J: Attention-deficit/hyperactivity disorder pharmacogenomics. Biol Psychiatry 2005, 57:1367-1373

17. Weinshilboum R: Inheritance and drug response. N Engl J Med 2003, 348:529-537.

18. Polanczyk G, Zeni C, Genro JP, Roman T, Hutz MH, Rohde LA: Attentiondeficit/hyperactivity disorder: advancing on pharmacogenomics. Pharmacogenomics 2005, 6:225-234.

19. Biederman J, Spencer T: Attention-deficit/hyperactivity disorder (ADHD) as a noradrenergic disorder. Biol Psychiatry 1999, 46:1234-1242.

20. Michelson D, Adler L, Spencer T, Reimherr FW, West SA, Allen AJ, et al: Atomoxetine in adults with ADHD: two randomized, placebo-controlled studies. Biol Psychiatry 2003, 53:112-120.

21. Mick E, Neale B, Middleton FA, McGough JJ, Faraone SV: Genome-wide association study of response to methylphenidate in 187 children with attention-deficit/hyperactivity disorder. Am J Med Genet B Neuropsychiatr Genet 2008, 147B:1412-1418.

22. Kaufman J, Birmaher B, Brent D, Rao U, Flynn C, Moreci P, et al: Schedule for Affective Disorders and Schizophrenia for School-Age ChildrenPresent and Life Time Version (K-SADS-PL): initial reliability and validity data. J Am Acad Child Adolesc Psychiatry 1997, 36:980-988.

23. Kim YS, Cheon KA, Kim BN, Chang SA, Yoo HJ, Kim JW, et al: The reliability and validity of Kiddie-Schedule for Affective Disorders and Schizophrenia - Present and Lifetime Version - Korean Version (K-SADSPL-K). Yonsei Med J 2004, 45:81-89.

24. DuPaul GJ: Parent and teacher ratings of ADHD symptoms: psychometric properties in a community-based sample. J Clin Child Psychol 1991, 20:245-253.

25. So YK, Noh JS, Kim YS, Ko SG, Koh SJ: The reliability and validity of Korean parent and teacher ADHD Rating Scale. J Korean Neuropsychiatr Assoc 2002, 41:283-289.

26. National Institute of Mental Health: CGI, Clinical Global Impressions. In Manual of the ECDEU Assessment Battery. Revised edition. Edited by: Guy W, Bonato R. Chevy Chase, Maryland: National Institute of Mental Health; 1970.

27. Cheon KA, Kim BN, Cho SC: Association of 4-repeat allele of the dopamine D4 receptor gene exon III polymorphism and response to methylphenidate treatment in Korean ADHD children. Neuropsychopharmacology 2007, 32:1377-1383.

28. Cheon KA, Cho DY, Koo MS, Song DH, Namkoong K: Association between homozygosity of a $\mathrm{G}$ allele of the alpha-2a-adrenergic receptor gene 
and methylphenidate response in Korean children and adolescents with attention-deficit/hyperactivity disorder. Biol Psychiatry 2009, 65:564-570.

29. Reimherr FW, Williams ED, Strong RE, Mestas R, Soni P, Marchant BK: A double-blind, placebo-controlled, crossover study of osmotic release oral system methylphenidate in adults with ADHD with assessment of oppositional and emotional dimensions of the disorder. J Clin Psychiatry 2007, 68:93-101.

30. Joung Y, Kim CH, Moon J, Jang WS, Yang J, Shin D, et al: Association studies of $-3081(\mathrm{~A} / \mathrm{T})$ polymorphism of norepinephrine transporter gene with attention deficit/hyperactivity disorder in Korean population. Am J Med Genet B Neuropsychiatr Genet 2010, 153B:691-694.

31. Gorwood P, Foot E: Introduction on Psychopharmacogenetics. In Psychopharmacogenetics. Edited by: Gorwood P, Hamon M. New York: Springer Science; 2006:1-24.

32. Faraone SV, Perlis R, Doyle AE, Smoller JW, Goralnick JJ, Holmgren MA, et al: Molecular genetics of attention-deficit/hyperactivity disorder. Biol Psychiatry 2005, 57:1313-1323.

33. Stein MA, McGough JJ: The pharmacogenomic era: promise for personalizing attention deficit hyperactivity disorder therapy. Child Adolesc Psychiatric Clin N Am 2008, 17:475-490.

34. Polanczyk G, Zeni C, Genro JP, Guimarães AP, Roman T, Hutz MH, et al: Association of the adrenergic alpha2A receptor gene with methylphenidate improvement of inattentive symptoms in children and adolescents with attention-deficit/hyperactivity disorder. Arch Gen Psychiatry 2007, 64:218-224.

35. Kooij JS, Boonstra AM, Vermeulen SH, Heister AG, Burger H, Buitelaar JK, et al: Response to methylphenidate in adults with $A D H D$ is associated with a polymorphism in SLC6A3 (DAT1). Am J Med Genet B Neuropsychiatr Genet 2008, 147B:201-208.

36. Solanto MV: Neuropsychopharmacological mechanisms of stimulant drug action in attention-deficit hyperactivity disorder: a review and integration. Behav Brain Res 1998, 94:127-152.

37. Newcorn JH, Kratochvil CJ, Allen AJ, Casat CD, Ruff DD, Moore RJ, et al: Atomoxetine/Methylphenidate Comparative Study Group: Atomoxetine and osmotically released methylphenidate for the treatment of attention deficit hyperactivity disorder: acute comparison and differential response. Am J Psychiatry 2008, 165:721-730.

doi:10.1186/1744-9081-6-57

Cite this article as: Kim et al:: Possible association of norepinephrine transporter $-3081(\mathrm{~A} / \mathrm{T})$ polymorphism with methylphenidate response in attention deficit hyperactivity disorder. Behavioral and Brain Functions $20106: 57$.

\section{Submit your next manuscript to BioMed Central and take full advantage of:}

- Convenient online submission

- Thorough peer review

- No space constraints or color figure charges

- Immediate publication on acceptance

- Inclusion in PubMed, CAS, Scopus and Google Scholar

- Research which is freely available for redistribution

Submit your manuscript at www.biomedcentral.com/submit
Biomed Central 